\title{
Napawanie laserowe powłok ochronnych na powierzchniach roboczych łopatek turbin parowych
}

\author{
Laser deposition of protective coatings \\ onto working area of steam turbine blades
}

\section{Streszczenie}

W procesie eksploatacji turbin parowych dochodzi do zużywania się łopatek wirnikowych. Łopatki pracujące w obszarach pary mokrej narażone są na erozję spowodowaną uderzeniami kropel cieczy oraz kawitację. Postępujące zużycie zmniejsza sprawność i moc całego bloku energetycznego. W pracy przedstawiono innowacyjną metodę zabezpieczania krawędzi łopatek poprzez laserowe napawanie warstw ochronnych. Napoiny wykonano laserem impulsowym Nd:YAG. Oględziny mikroskopowe oraz pomiary mikrotwardości potwierdziły poprawność przeprowadzonego procesu, właściwe wymieszanie napoiny z materiałem podłoża i otrzymanie pożądanej ciągłości metalurgicznej. Zastosowanie takiej metody regeneracji może wydłużyć czas pracy turbiny i pozwoli uniknąć konieczności wczesnej wymiany elementów na nowe, ograniczając koszt i czasochłonność prac naprawczych.

Słowa kluczowe: napawanie laserowe; powłoki ochronne; łopatki turbin parowych

\begin{abstract}
During the normal operations of steam turbine, the rotor's blades are wearing down. In the last stages of steam turbines, droplets are generating from the wet steam flow. Impacting droplets and cavitation cause erosion of blades. Progressive erosion has a bad influence on efficiency and power of turbo generators. The paper presents an innovative method of laser cladding to protect blades against erosion. Layers were made by Nd:YAG laser welding machine. Microscope inspection confirmed correctness of cladding process conducted, proper dilution of overlays with the substrate, and desired metallurgical continuity of overlays and substrate. The use of such methods, may extend steam turbine's usability, and avoid having to early replace components with new.
\end{abstract}

Keywords: laser cladding; protective coatings; steam turbine blades

\begin{abstract}
Wstęp
Siłę prężności pary znano i wykorzystywano już w zamierzchłych czasach, jednakże były to proste zastosowania do czynności w życiowych ówczesnego człowieka. Pierwsze zastosowanie przemysłowe sięga XVIII wieku, kiedy to szkocki inżynier James Watt skonstruował tłokową maszynę parową, zamieniającą ruch posuwisto-zwrotny tłoka na ruch obrotowy za pomocą układu korbowego. Historia turbin parowych, będących przedmiotem niniejszej pracy przypada na koniec XIX wieku. W 1884 r brytyjski inżynier Charles Parsons skonstruował pierwszą turbinę parową. Z biegiem czasu i rozwoju techniki, świadomość inżynierów, że para jest znakomitym nośnikiem energii w maszynach przepływowych, spowodowała szereg modyfikacji konstrukcyjnych i technologicznych zwiększających sprawność turbin oraz moc sięgającą kilkuset MW. Głównymi elementami konstrukcyjnymi turbin parowych kondensacyjnych są odpowiednio zamocowane na wale łopatki (Rys. 1), dzięki którym energia kinetyczna pary wodnej wprawia wirnik w ruch obrotowy. Łopatki oraz pozostałe części znajdujące się wewnątrz korpusu, na początkowych stopniach turbiny pracują
\end{abstract}

w warunkach podwyższonej temperatury (przegrzana para dochodząca z kotła osiąga temperaturę ok. $500^{\circ} \mathrm{C}$ ) oraz wysokiego ciśnienia [1 $\div 4]$.

W kolejnych stopniach turbiny w wyniku rozprężania się pary, ciśnienie i temperatura obniżają się i po przekroczeniu tzw. linii Wilsona, dochodzi do wydzielania z pary dużej liczby kropelek cieczy. Pomimo zastosowania zaawansowanych materiałów żarowytrzymałych, odpornych na korozję i erozję oraz precyzyjnego procesu wytwarzania topatek, długotrwała eksploatacja we wspominanych wyżej warunkach powoduje ich zużycie. Wraz ze wzrostem stopnia zużycia obniża się sprawność i moc całego bloku energetycznego $[3,5]$.

Współczesna energetyka staje przed dylematem, czy wymieniać zużyte części na nowe, czy też próbować je regenerować? Wytwarzanie nowych części jest bardzo kosztowne i może znacząco obciążać środowisko naturalne. W obecnej sytuacji ekonomicznej z pomocą przychodzą spawalnicze metody regeneracji i modyfikacji powierzchni. Umożliwiają one odtwarzanie właściwości eksploatacyjnych części maszyn znacznie niższym nakładem finansowym, niekiedy

Inż. Konrad Tobota; dr hab. inż. Tomasz Chmielewski, prof. PW - Politechnika Warszawska.

Autor korespondencyjny/Corresponding author: konradtob@gmail.com 
elementy po regeneracji wykazują lepsze właściwości niż nowo wyprodukowane [6].

Dzisiejsza inżynieria spajania oferuje szereg technologii modyfikacji i regeneracji powierzchni. Do najczęściej stosowanych należą metody napawania łukowego $[7,8]$ z grupy GMA. Coraz częściej do napawania zaawansowanych części maszyn stosowane jest napawanie plazmowe oraz laserowe $[9,10]$. W pracy będącej przedmiotem niniejszego artykułu wykorzystano technologię napawania laserowego, laserem impulsowym Nd:YAG.

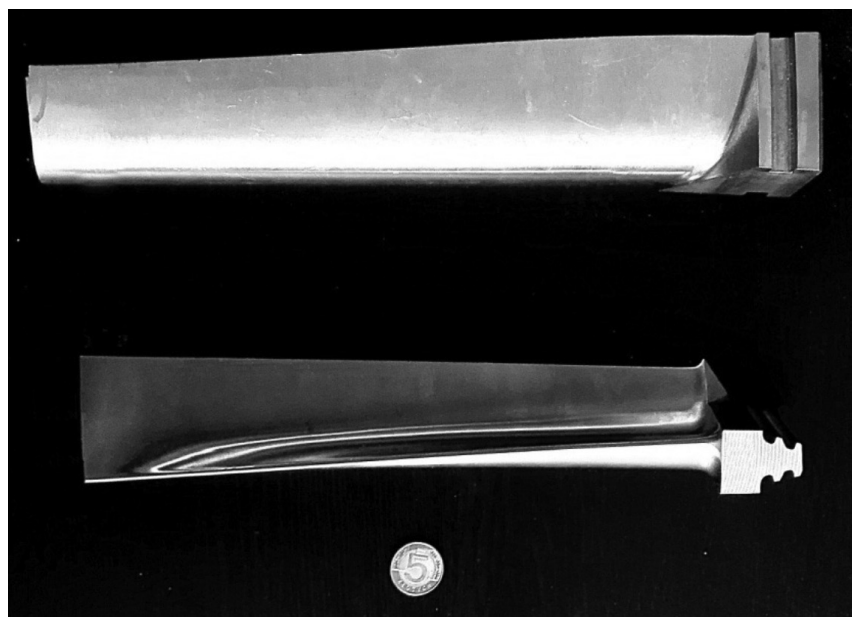

Rys. 1. Przykładowe łopatki turbiny parowej kondensacyjnej

Fig. 1. Examples of condensing steam turbines blades

\section{Mechanizmy zużycia łopatek turbin parowych}

W turbinach parowych, łopatki pracują zarówno w warunkach podwyższonej temperatury charakterystycznej dla przegrzanej pary (ok. $\left.500^{\circ} \mathrm{C}\right)$, jak i w strefach niskoprężnych, gdzie zaczyna się obszar pary mokrej, w którym łopatki mają bezpośredni kontakt z kroplami cieczy, powstałymi w wyniku spontanicznej kondensacji pary.

Problem zużycia łopatek wirnikowych nie dotyczy jedynie erozji materiału spowodowanej uderzeniami kropel zarówno pierwotnych jak i wtórnych. Należy pamiętać także, o zużyciu mechanicznym i zmęczeniowym. Mając na uwadze, że wirnik turbiny parowej obraca się z dużą prędkością rzędu od kilku do kilkudziesięciu tysięcy obrotów na minutę, mamy do czynienia z ogromną siłą odśrodkową powodującą pełzanie materiału. Cyklicznie zmienne prędkości obrotowe

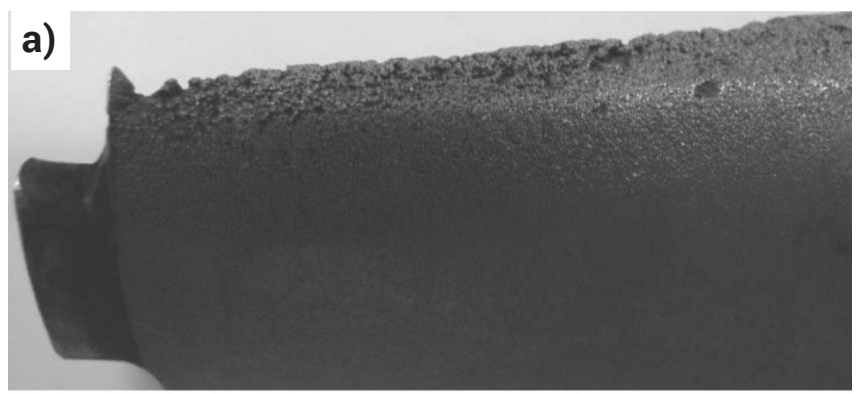

b)

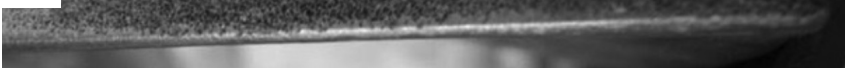

Rys. 2. Erozyjne ubytki materiału na krawędzi natarcia łopatki a) [11], zużycie kawitacyjne łopatki [11], b)

Fig. 2. Erosion defects on the blades edge, a) [11], cavitation wear of blade, b) [11] generują zmienne naprężenia, odpowiedzialne za zużycie zmęczeniowe łopatek i powstawanie pęknięć. Negatywny wpływ mają także drgania mechaniczne towarzyszące każdej pracującej maszynie. Wyżej wspomniane ubytki erozyjne są obszarami koncentracji naprężeń, a tym samym początkiem złomu zmęczeniowego. Częste zmiany obciążenia i duże prędkości nagrzewania elementów metalowych, skutkują również stosunkowo szybkim zmęczeniem cieplnym. Deformacje cieplne mogą prowadzić do trwałych odkształceń elementów turbiny $[4,11]$. Na rysunku 2 przedstawiono erozyjne oraz kawitacyjne zużycie łopatek turbiny parowej.

Dotychczas zabezpieczano narażone na zużycie krawędzie poprzez natryskiwanie powłok metalicznych i kompozytowych lub stosowano nakładki ochronne (rys. 3.) np. tytanowe, spajane z powierzchnią łopatek za pomocą lutów. Żadna z powyższych metod nie zapewniała pożądanej ciągłości metalurgicznej i wymieszania z materiałem podłoża, dlatego też w niniejszej pracy zastosowano innowacyjną technologię napawania laserowego.

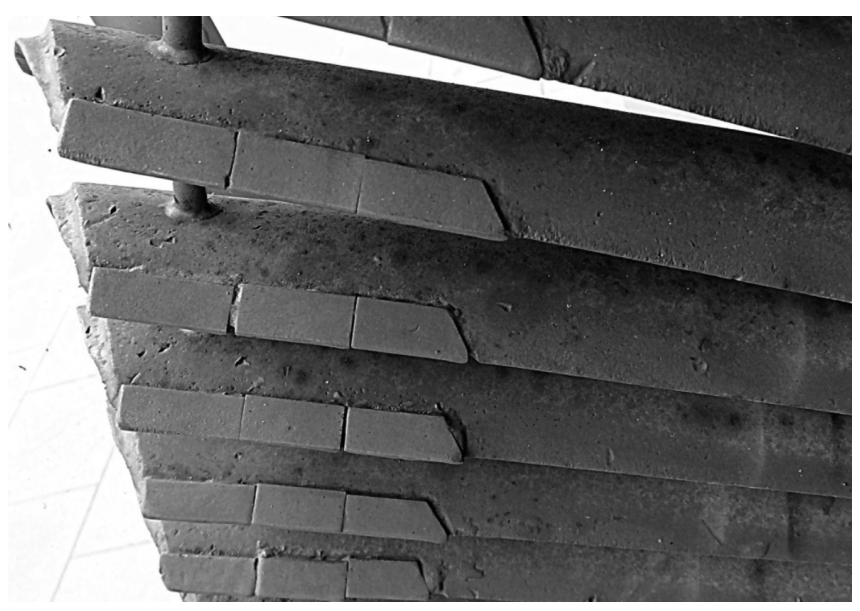

Rys. 3. Łopatki wirnika turbiny parowej TC25 - łopatki regenerowane za pomocą nakładek [12]

Fig. 3. TC25 Steam turbine rotor's blades - example of regeneration using overlays [12]

\section{Stosowane materiały}

W pierwszym etapie opracowywania technologii napawania wykonano badanie składu chemicznego łopatki. Badanie przeprowadzono przy użyciu spektrometru jarzeniowego. W celu poprawności wnioskowania na łopatce będącej przedmiotem pracy wykonano 3 próby (rys. 4) i uśredniono wyniki.

Uśredniony wynik z 3 prób badania składu chemicznego łopatki przedstawia tablicy I.

Otrzymany wynik porównano z dostępnymi tablicami składów chemicznych stali i wytypowano stal kotłową, żarowytrzymałą X22CrMoV12-1 (1.4923).

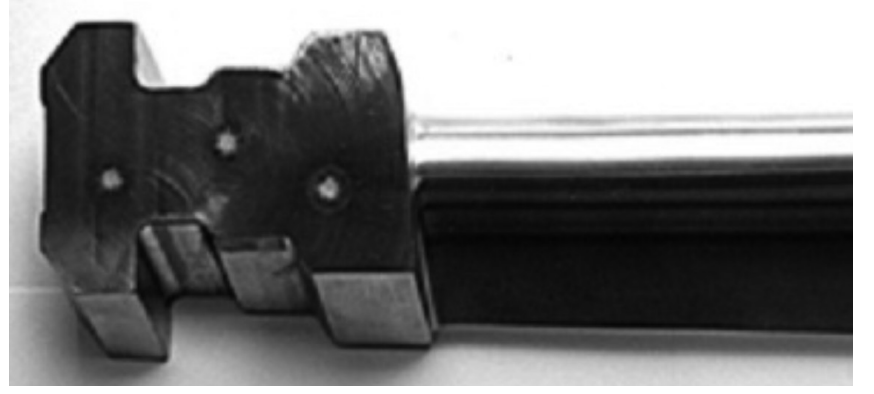

Rys. 4. Widocznie 3 przypalenia spektrometrem iskrowym na powierzchni łopatki

Fig. 4. Visible three trials of spark spectrometer on a blade's surface 
W celu wstępnego określenia mikrostruktury tej stali obliczono równoważnik chromu oraz niklu $\left(\mathrm{Ni}_{\mathrm{E}}=13,2 \%\right.$, $\left.\mathrm{Cr}_{\mathrm{E}}=7,3 \%\right)$. Wg wykresu Schaefflera, jest to stal o strukturze martenzytycznej, której spawalność metalurgiczna jest znacząco ograniczona [13]

Jako materiał dodatkowy do napawania dobrano drut chromowo-niklowy o średnicy 0,5 mm firmy Quada V+F Laserschweißdraht GmbH o symbolu QuMed4551 stosowany do łączenia i napawania stali martenzytycznych odpornych na korozję i wysoką temperaturę. Skład chemiczny drutu wg danych producenta przedstawia tablica II.

Tablica I. Skład chemiczny topatki

Table I. The chemical composition of a blade

\begin{tabular}{|c|c|c|c|c|c|c|c|c|}
\hline \multicolumn{7}{|c|}{ Zawartość pierwiastków, \% wag. } \\
\hline Fe & C & Cr & Mo & Ni & Mn & Si & V & Nb \\
\hline 84 & 0,23 & 12 & 0,81 & 0,9 & 0,74 & 0,23 & 0,4 & 0,11 \\
\hline
\end{tabular}

Tablica II. Skład chemiczny drutu QuMed4551 [14]

Table II. The chemical composition of QuMed4551 wire [14]

\begin{tabular}{|c|c|c|c|c|c|c|c|}
\hline Pierwiastek & $\mathbf{C}$ & $\mathbf{M n}$ & $\mathbf{S i}$ & $\mathbf{N i}$ & $\mathbf{C r}$ & $\mathbf{N b}$ & $\mathbf{V}$ \\
\hline $\begin{array}{c}\text { Zawartość } \\
\text { [\%], wag. }\end{array}$ & $<0,06$ & 1,3 & 0,85 & 9,5 & 19,5 & 0,72 & 0,25 \\
\hline
\end{tabular}

\section{Opis metody napawania}

Promieniowanie laserowe jest szczególnym rodzajem promieniowania elektromagnetycznego. Polega na wzmocnieniu światła poprzez wymuszoną emisję promieniowania w wyniku przejść energetycznych elektronów pomiędzy stanami o wyższej i niższej energii, w ośrodku czynnym lasera. Ośrodkiem czynnym laserów stosowanych w spawalnictwie jest zazwyczaj gaz lub ciało stałe. Napawanie powłok modyfikacyjnych wykonano laserem impulsowym na ciele stałym Nd:YAG, w którym podstawowym elementem generatora jest pręt wykonany $z$ materiału krystalicznego, granatu itrowo-aluminiowego $\left(\mathrm{Y}_{3} \mathrm{Al}_{5} \mathrm{O}_{12}\right)$ z domieszką (3\%) jonów neodymu $\mathrm{Nd} 3+$, emitującego promieniowanie o długości fali $1,06 \mu \mathrm{m}[15 \div 17]$.

\section{Badania własne}

Próby napawania laserowego prowadzono przy użyciu urządzenia OR Laser EVO Mobile (rys. 5.) [20] w firmie RESURS przy ul. Czarodzieja 12 w Warszawie. Zgodnie z wynikiem analizy mechanizmów zużycia, zabezpieczono kra-

Tablica III. Główne parametry procesu napawania laserem Nd:YAG Table III. Main parameters of ND:YAG laser cladding process

\begin{tabular}{|c|c|}
\hline Parametr & Wartość \\
\hline Napięcie & $450[\mathrm{~V}]$ \\
\hline Moc & $195[\mathrm{~W}]$ \\
\hline Moc impulsu & $6,92[\mathrm{~kW}]$ \\
\hline Energia impulsu & $21,7[\mathrm{~J}]$ \\
\hline Szerokość impulsu & $7,5[\mathrm{~ms}]$ \\
\hline Częstotliwość & $9,0[\mathrm{~Hz}]$ \\
\hline
\end{tabular}

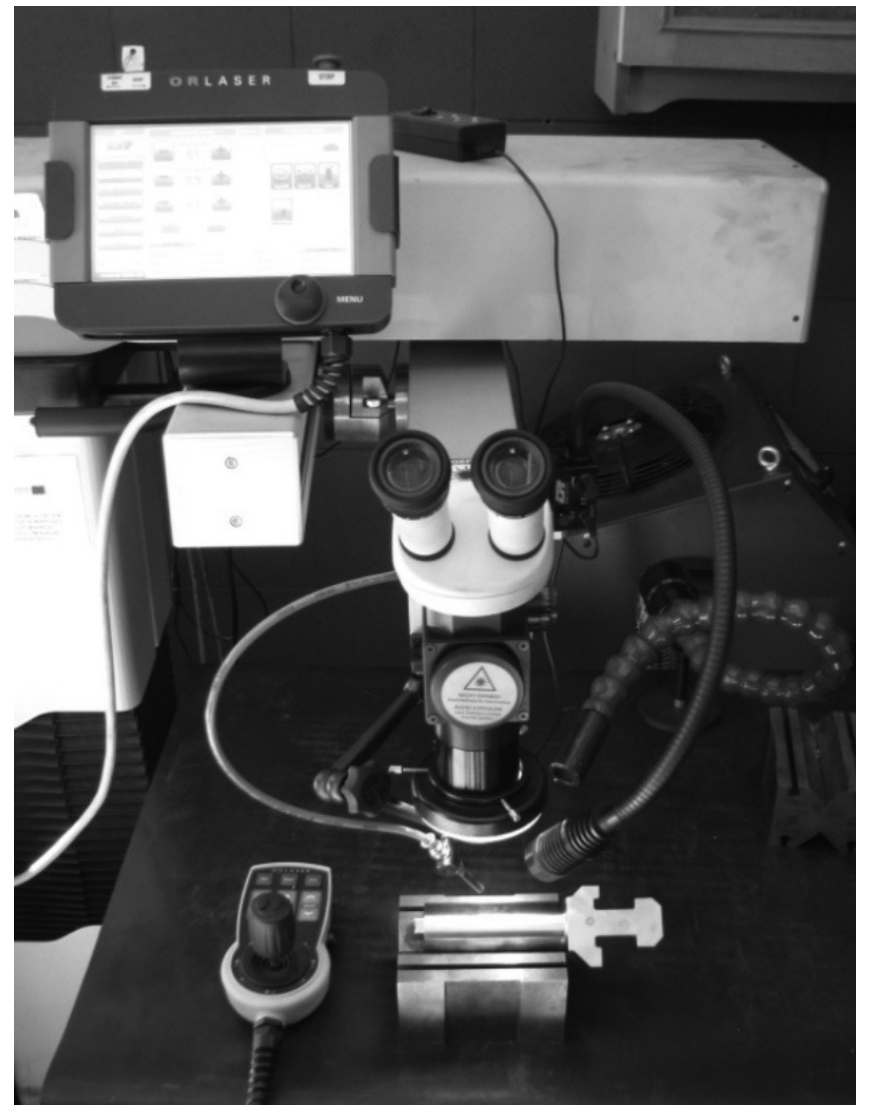

Rys. 5. Urządzenie do napawania OR Laser EVO Mobile [18] Fig. 5. OR Laser EVO Mobile laser welding machine [18]

wędź natarcia pióra łopatki - 1 próba, 3 ściegi; 2 próba, 5 ściegów oraz krawędź spływu - napoina jednościegowa krawędziowa. Napoiny wykonano zgodnie z parametrami zamieszczonymi w tablicy III.

Po wykonaniu napoin pobrano odpowiednie próbki do badań mikroskopowych. Badania metalograficzne przeprowadzono w celu ujawnienia mikrostruktury, określenia stopnia wymieszania napoiny z metalem podłoża, pomiaru wielkości geometrycznych oraz określenia zasięgu strefy wpływu ciepła. Oględziny mikroskopowe, poprzedziła precyzyjna preparatyka zgładów, szlifowanie, polerowanie oraz trawienie odczynnikiem Mi16Fe.

Rysunek 6 przedstawia mikrostrukturę materiału łopatki, jest to stal o strukturze martenzytycznej.

Obraz mikroskopowy napoiny krawędziowej jednościegowej wykonanej na krawędzi spływu pióra łopatki przedsta-

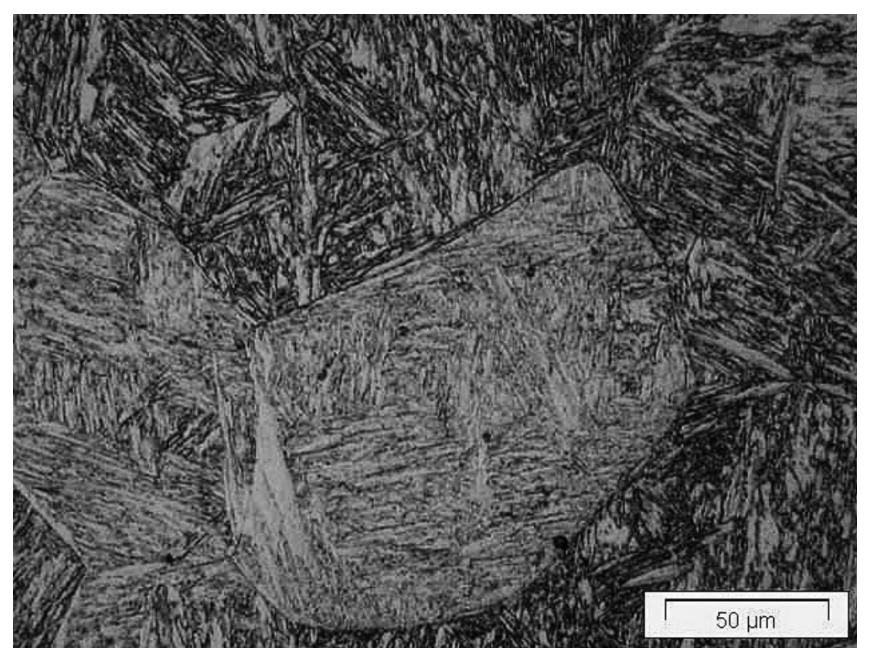

Rys. 6. Mikrostruktura topatki ze stali X22CrMoV12-1, x500 Fig. 6. Blade's microstructure of X22CrMoV12-1 steel, $x 500$ 
wia rysunek 7. Napoinę obserwowano przy powiększeniu 50-krotnym. Uzyskano kształt odpowiadający pierwotnej geometrii krawędzi łopatki. Niewidoczny wpływ cyklu cieplnego napawania w okolicy linii wtopienia. Z uwagi na małą objętość materiału na krawędzi, doszło do znacznego wymieszania napoiny z podłożem. Niska masa krawędzi i wynikająca z tego niska pojemość cieplna tego obszaru skutkowała stosunkowo powolnym stygnięciem w SWC.

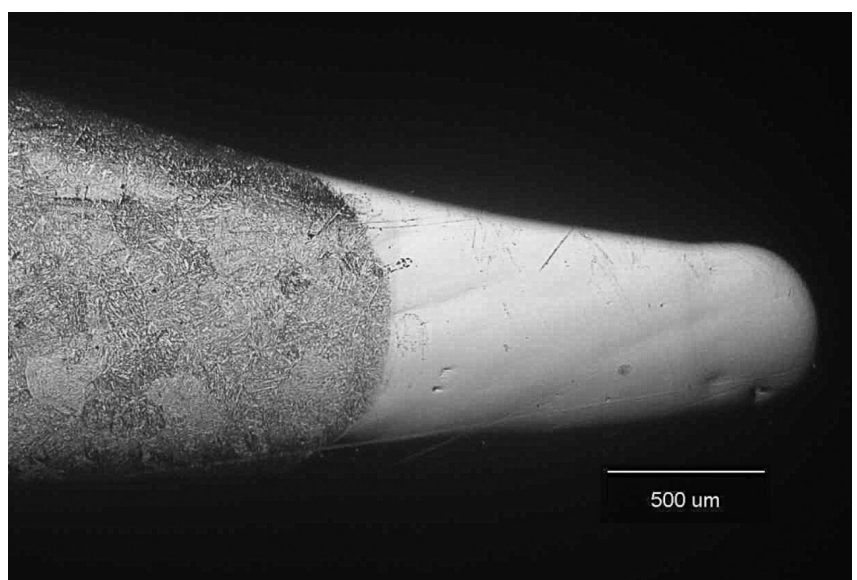

Rys. 7. Napoina laserowe na krawędzi spływu pióra łopatki, x50 Fig. 7. Laser pad weld on a blade's trailing edge, $x 50$

Szerokość napoiny w przedziale 530 - $950 \mu \mathrm{m}$ począwszy od ostrej krawędzi. Długość $1400 \mu \mathrm{m}$. Głównym zadaniem otrzymanej warstwy jest ochrona krawędzi przed kontaktem z kroplami cieczy, powodującymi ubytki erozyjne.

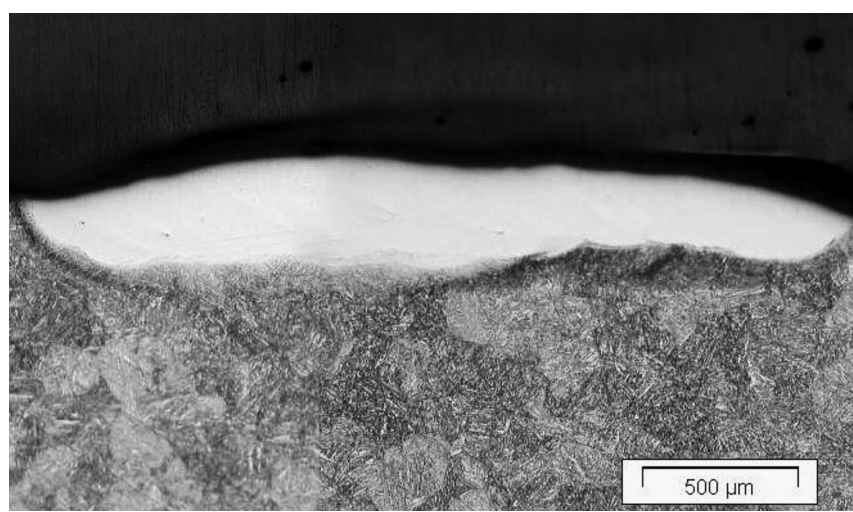

Rys. 8. Napoina laserowe na krawędzi spływu pióra łopatki, x50 Fig. 8. Laser pad weld on a blade's trailing edge, $x 50$

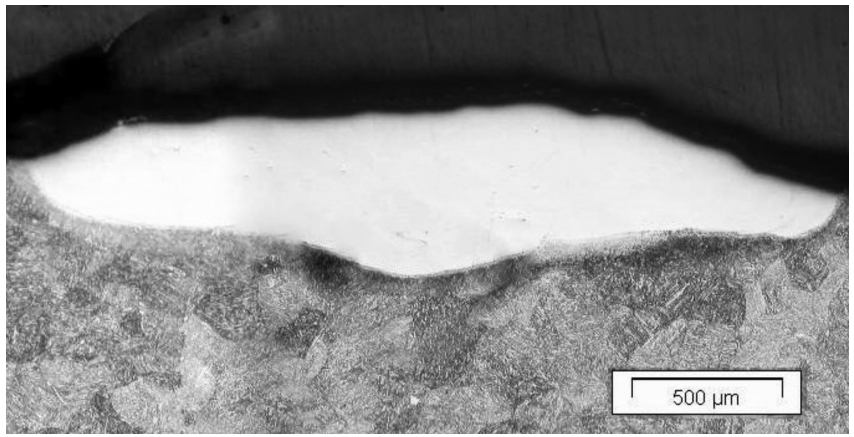

Rys. 9. Napoina laserowe na krawędzi spływu pióra łopatki, x50 Fig. 9. Laser pad weld on a blade's trailing edge, x50

W kolejnej próbie wykonano napoinę 3-ściegową na krawędzi natarcia (rys. 8). Stosowano temperaturę międzyściegową $50{ }^{\circ} \mathrm{C}$, w celu uniknięcia negatywnego wpływu złożonego cyklu cieplnego i przegrzania podłoża.

Widoczny zasięg strefy wpływu ciepła 100-150 $\mu \mathrm{m}$. Szarokość napoiny $2606 \mu \mathrm{m}$, wysokość 200-350 $\mu \mathrm{m}$. Struktura podłoża martenzytyczna.

Następnie wykonano analogiczną napoinę 5-ściegową (rys. 9.) Pomimo dodatkowych cykli cieplnych, zasięg strefy wpływu ciepła nie przekroczył $120 \mu \mathrm{m}$.

Kolejnym etapem badań były pomiary mikrotwardości. Zastosowano metodę Vickersa polegającą na wciskaniu w materiał diamentowego ostrosłupa o podstawie kwadratu i kącie między ścianami $136^{\circ}$. Warunki badania określa PN-EN ISO 6507-1. Pomiary wykonano pod obciążeniem 1 N, wyniki zobrazowano na wykresie (rys. 10).

Pomiar mikrotwardości przeprowadzono począwszy od linii wtopienia w kierunku lica napoiny, oraz w stronę materiału podłoża przez SWC, zachowując odległości 0,05 $\mathrm{mm}$ między odciskami. Zaznaczone na wykresie wartości reprezentują średnią arytmetyczną czterech pomiarów, których odchylenie standardowego nie przekraczało wartości 10. W przypadku napoiny 3-ściegowej zaobserwowano podwyższoną twardość w SWC rzędu $400 \mu \mathrm{HV}$. Zbyt wysoka twardość w strefie wpływu ciepła może być powodem powstawania kruchych pęknięć. Dodatkowe cykle cieplne napawania w przypadku napoiny 5-ściegowej nie miały wpływu na zasięg i twardość SWC. Otrzymano rozkład mikrotwardości bardzo zbliżony do napoiny 3-ściegowej. Zgodnie z tezą postawioną podczas oględzin mikroskopowych, brak wyraźnych zmian twardości w SWC w napoinie krawędziowej jest efektem jednoczesnego oddziaływania wyższego wymieszania materiału napoiny z podłożem i wolniejszego odprowadzania ciepła, niż podczas napawania w bardziej masywnych obszarach łopatki.

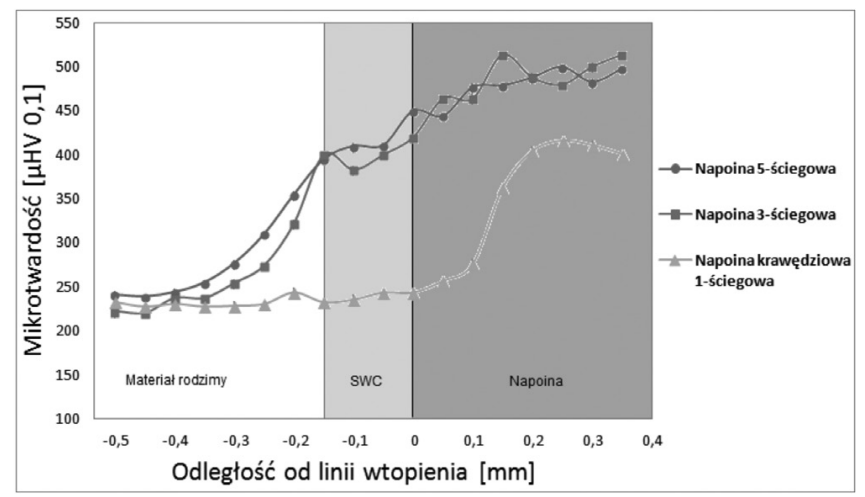

Rys. 10. Rozkład mikrotwardości w przekroju podłoże-napoina

Fig. 10. Distribution of microhardness in cross-section in substrate material and pad weld 


\section{Podsumowanie}

Na podstawie przeprowadzonej analizy literaturowej zagadnienia zużycia łopatek turbin parowych, oraz metod ich regeneracji, wytypowano metodę oraz warunki technologiczne napawania prewencyjno-naprawczego. Precyzyjny, pod względem kontroli ilości wprowadzanego ciepła proces napawania przy użyciu lasera impulsowego Nd:YAG drutem litym Cr-Ni pozwolił uzyskać powłoki, które zgodnie ich charakterystyką są odporne na zużycie erozyjne i kawitacyjne. Uzyskanych powłok jeszcze nie testowano w warunkach eksploatacyjnych. Ochronne powłoki wykonano na krawędziach natarcia oraz spływu, czyli w obszarach najsilniej narażonych na powstawanie ubytków. Przeprowadzone badania mikroskopowe struktury oraz pomiary mikrotwardości potwierdziły poprawność wykonanych napoin na krawędzi spływu.

W obszarze masywnej krawędzi natarcia, w której to strefie ciepło było szybko rozpraszane w masie łopatki, doszło do znacznego utwardzenia w SWC (pomimo wielościegowego napawania). Zapobiegawczo należy wprowadzić podgrzewanie wstępne i międzyściegowe. Zastosowanie, opisanego w artykule procesu napawania prewencyjnego, który może również mieć charakter regeneracyjny, może znacząco zwiększyć trwałość dotychczas stosowanych łopatek.

Autorzy artykułu składają podziękowania Panu Andrzejowi Radziszewskiemu, właścicielowi firmy RESURS przy ul. Czarodzieja 12 w Warszawie za udostępnienie stanowiska laserowego oraz materiałów dodatkowych do napawania.

\section{Literatura}

[1] W. Chrzanowski „Turbiny Parowe Biblioteki Dzieł Technicznych”, Tom IV, Warszawa 1920.

[2] T. Nikiel „Turbiny Parowe” WNT, Warszawa 1989

[3] A. Korpela Seppo "Steam Turbines. Principles of Turbomachinery", Chapter 5, John Wiley \& Sons Inc. USA 2012

[4] J. Badur, S. Kornet „Nierównowagowe przemiany fazowe” Logistyka 4/2013, Poznań 2013

[5] J. Dobrzański, A. Hernas „Trwałość i niszczenie elementów kotłów i turbin parowych" WPŚ, Gliwice 2003

[6] T. Chmielewski, D. Golański „Znaczenie spawalnictwa w procesie remanufacturingu" Przegląd Spawalnictwa Vol 83, No 6/2011, Warszawa 2011

[7] T. Chmielewski, M. Węglowski „Analiza rynku spawalniczego w Polsce pod względem sprzedaży urządzeń oraz materiałów spawalniczych", Przegląd Spawalnictwa, vol. 82 (6), s. 28-31, 2010.

[8] M. Węglowski, T. Chmielewski, K. Kudła „Porównanie wybranych właściwości nowoczesnych spawalniczych inwertorowych źródeł energii przeznaczonych do spawania metodą MAG", Przegląd Spawalnictwa, vol. 81 (10), s.81-83, 2009.

[9] M. Bober, J. Senkara „Mikrostruktura kompozytowych powłok Ni-ZrC napawanych plazmowo", Przegląd Spawalnictwa, vol. 87 (10), s.60-63, 2015.
[10] M. Bober, K. Tobota „Badania istotności wpływu podstawowych parametrów napawania plazmowego na geometrię napoin” Przegląd Spawalnictwa, vol. 87 (9), s.24-28

[11] A. Iwaniak, M. Hetmańczyk „Zabezpieczanie łopatek turbin parowych przed niszczeniem erozyjnym powłokami ochronnymi napawanymi laserowo" Tribologia 2-2012 SIMP, Warszawa 2012

[12] Eksponat wirnika turbiny parowej TC25 eksploatowanej w E.C. Żerań. Ofiarowany Instytutowi Techniki Cieplnej PW przez Vattenfall.

[13] T Chmielewski „Projektowanie procesów technologicznych - Spawalnictwo" Oficyna Wydawnicza Politechniki Warszawskiej, Warszawa 2013.

[14] Quada V+F Laserschweißdraht GmbH www.quada-office.com

[15] A. Klimpel „Technologie Laserowe w Spawalnictwie” Wydawnictwo Politechniki Śląskiej, Gliwice 2011

[16] Z. Bogdanowicz, K. Grzelak, W. Napadłek „Laserowe kształtowanie warstwy powierzchniowej elementów maszyn" WAT, Warszawa 2011

[17] J. Wilden „Laserauftragschweißen” Przegląd Spawalnictwa Vol 83, 9/2011, Warszawa 2011

[18] Własność firmy „RESURS” A. Radziszewski, Warszawa 2016 